\title{
Avaliação sobre a Avaliação de Ciências no Paraná (1996-2000)
}

\author{
MARCOS CESAR DANHONI NEVES \\ Coordenador do Programa de Mestrado em Educação para a Ciência e o Ensino de \\ Matemática. Universidade Estadual de Maringá \\ macedane@yahoo.com
}

SILVIA DE OLIVEIRA RESQUETTI

Mestranda em Educação para a Ciência e o Ensino de Matemática

Universidade Estadual de Maringá

sresquetti@uol.com.br

\section{Resumo}

O presente trabalho busca olhar em perspectiva o processo de avaliação de ciências na rede pública do Estado do Paraná, no período de 1996 a 2000. São mostrados e discutidos os resultados relativos aos exames de proficiência, além de dados sociais e da política de livros didáticos.

Palavras-chave: ensino de ciências, avaliação da aprendizagem, avaliação de projeto.

\section{Resumen}

El presente artículo hace un analisis en perspectiva del proceso de evaluación de las ciencias en el sistema educativo público del Estado del Paraná, en el período 1996 a 2000. Se exponen y discuten los resultados relativos a los examenes de competencia, además de datos sociales y de la política de los libros de texto.

Palabras-clave: enseñanza de las ciencias, evaluación de aprendizaje, evaluación de proyectos.

\footnotetext{
Abstract

This paper aims to look in perspective at the process of evaluation in Sciences in the Public Educational System of Paraná State, during the period 1996-2000. The results relating to proficiency exams, as well as social data and the policy of textbooks are shown and discussed.

Key words: science teaching, learning assessment, assessment of projects
} 
O Projeto Avaliação do Rendimento Escolar (AVA), realizado no final do século XX pela Secretaria de Educação do Estado do Paraná, tinha como objetivo principal:

conhecer os resultados efetivos do sistema educacional paranaense, em termos de habilidades e conhecimentos adquiridos pelos alunos, abrangendo, para isso, o universo das escolas da rede pública estadual e, de forma optativa, escolas municipais e particulares. (Paraná, 2001)

A primeira avaliação com esse objetivo foi realizada em 1996, envolvendo ciências naturais, mas o universo era constituído somente por alunos da $8^{a}$ série do Ensino Fundamental. Em 1997, essa avaliação passou a incluir também a $4^{\mathrm{a}}$ série.

A base curricular na qual esse processo avaliativo ocorria era o "Currículo Básico para a Escola Pública do Estado do Paraná" (1992, p. 123144). Essa formatação curricular buscava estabelecer referenciais para uma ação pedagógica em Ciências. No que diz respeito ao Ensino Fundamental ( $1^{\mathrm{a}}$ à $8^{\mathrm{a}}$ séries), a proposta "Currículo Básico para Ciências" estava organizada em três grandes eixos temáticos: noções de astronomia; transformação e interação da matéria e energia; saúde e melhoria da qualidade de vida.

Esses eixos eram retomados em todas as séries com um aprofundamento progressivo dos conteúdos. Apesar de toda a estrutura teórica, que buscava enfatizar aspectos sociais e históricos, o currículo primava ainda pela quase inabalável compartimentalização de conteúdos.

A implantação desse currículo se deu de forma irregular, uma vez que se esperava de cada escola uma organização própria e preliminar de seus currículos. Porém, como era de se esperar, isso ocorria de forma muita lenta e cheia de percalços, em razão do atrelamento às políticas educacionais orientadoras dos conteúdos de conhecimento.

Esse processo, interminável, começou a estagnar em 1998, com a publicação dos Parâmetros Curriculares Nacionais - PCNs, pois cada Estado da União poderia organizar seus conteúdos pedagógicos e estabelecer sua orientação pedagógica. Isso levou um grande temor aos professores (e mesmo à Secretaria Estadual de Educação), especialmente no Estado do Paraná, onde prevaleceu a idéia de que os "Parâmetros" acarretariam novos problemas, em especial dois: a "convivência" com o "velho currículo de 1992" e as "dificuldades" que apareceriam para alunos transferidos de outros Estados.

Um outro aspecto que dificultou a implantação do currículo de 1992, assim como nos anos iniciais da implantação dos "Parâmetros", foram os livros didáticos existentes na época. Os livros seguiam uma lógica 
tradicional de estruturação, encadeamento e seleção de conteúdos. Mesmo com a implantação do "Programa Nacional do Livro Didático" (PNLD), pelo MEC, esse problema ainda persiste, como analisaremos mais adiante.

\section{ANÁLISE DAS MATRIZES DA AVA PARANÁ}

As avaliações do sistema de ensino no Paraná nunca apresentaram um objetivo claramente definido ao seu público, ou seja, aos professores da Rede Pública de Ensino Fundamental do Estado: ou se tratava de uma busca por políticas públicas para a melhoria do ensino ou se tratava apenas de uma "ilustração" dentro de políticas mais generalistas do governo de plantão.

Freitas (2005) nos dá uma provável resposta para essa questão:

As variações nos motivos para a utilização da avaliação como expediente de governo da educação básica parecem estar relacionadas a distintos compromissos do Estado. No caso brasileiro, foi primeiramente coerente com compromissos priorizados pelo Estado nacional-desenvolvimentista e, mais recentemente, pelos compromissos de um Estado instalado, pela própria globalização e pela força do ideário neoliberal, a se tornar um "Estado competitivo". (p.96)

Supondo que a primeira vertente seja aquela mais crível, ou seja, a de um caráter diagnóstico, os diferentes processos de avaliação ao longo dos anos, especialmente os de 1996, 1997, 1998 e 2000, adotaram como referência os currículos de plantão: o de 1992 até o período anterior aos PCNs e os de 1998 em diante. Os currículos ou parâmetros delineavam a seleção de conteúdos para a composição das provas aplicadas aos estudantes.

Os conteúdos selecionados para as ciências da natureza dentro dessa proposta partiam dos seguintes pressupostos principais:

- explicitação do dinamismo das transformações de matéria e energia, objetivando a possibilidade de seu domínio pelo homem e a ação deste na natureza;

- reconhecimento de que as ações decorrentes do conhecimento científico e tecnológico ocorrem dentro de um contexto histórico, o qual condiciona efeitos nos campos social, econômico e político;

- questionamento crítico do conteúdo específico, incluindo a compreensão do mesmo dentro da realidade social;

- organização da prática pedagógica sustentada a partir dos eixos para melhor articulação dos conteúdos e da avaliação. 
A seleção e organização dos conteúdos dentro dos eixos, para a $8^{\text {a }}$ série, e os conteúdos contemplados nas matrizes da avaliação de 1996 e 1997, podiam ser resumidos em três grandes eixos temáticos já citados anteriormente. É de se salientar que no currículo proposto para ciências naturais da $8^{\mathrm{a}}$ série, tanto a química quanto a física não eram apontadas explicitamente como conteúdos de base, mas eram associadas a tópicos de fisiologia, de saúde humana e alimentos. A biologia era trabalhada associada à saúde e ao homem, enquanto a astronomia era trabalhada, muito pobremente, em conteúdos relacionados à astronáutica.

Havia, portanto, uma visão utilitarista da ciência, no sentido de buscar no "fazer da ciência" a sua compreensão efetiva. Essa concepção acabou por impregnar a organização da matriz de avaliação. A associação das ciências naturais aos sistemas do corpo humano e à saúde, por exemplo, era uma proposta que era seguida apenas em parte pelos textos didáticos. Podia-se inferir, assim, que o trabalho nas escolas tendia a apresentar um caráter mais amplo de diferenciação em relação à matriz de trabalho.

As matrizes de 1996 e 1997 não apresentavam diferenças sensíveis em termos de conteúdo. As alterações eram muito pequenas; nada digno de nota. As matrizes de 2000, tanto para a $4^{a}$ quanto para a $8^{a}$ séries do Ensino Fundamental, apresentavam um quadro de "competências" para cada conteúdo, como ilustrado nas tabelas 1 e 2 . 
Tabela 1 - Matriz de Competência 2000 - Ciências - $4^{\text {a }}$ Série

\begin{tabular}{|c|c|c|c|}
\hline ÁREA & \multicolumn{2}{|c|}{ DESCRITOR } & CONTEÚDO \\
\hline \multirow{3}{*}{$\begin{array}{l}\text { I. Terra e } \\
\text { Universo }\end{array}$} & 1 & 1 & Reconhecer as condições necessárias à existência e manutenção de vida no planeta. \\
\hline & 2 & 7 & Relacionar o movimento de translação a fatores climáticos. \\
\hline & 3 & 30 & Relacionar o intervalo de tempo de um dia com o movimento de rotação da Terra. \\
\hline \multirow{13}{*}{$\begin{array}{l}\text { II. Seres } \\
\text { Vivos, } \\
\text { Ambiente e } \\
\text { Sociedade }\end{array}$} & 4 & 2 & $\begin{array}{l}\text { Reconhecer que os seres vivos e os elementos físico-químicos do ambiente estão em } \\
\text { constante interação. }\end{array}$ \\
\hline & 5 & 3 & Inter-relacionar água e seres vivos num ecossistema. \\
\hline & 6 & 4 & $\begin{array}{l}\text { Analisar as responsabilidades individual e coletiva, em relação ao equilíbrio } \\
\text { ambiental e/ou à saúde pública. }\end{array}$ \\
\hline & 7 & 5 & $\begin{array}{l}\text { Relacionar a interdependência entre os componentes de um ecossistema e a } \\
\text { manutenção da vida. }\end{array}$ \\
\hline & 8 & 6 & Reconhecer a importância da coleta seletiva do lixo. \\
\hline & 9 & 8 & $\begin{array}{l}\text { Estabelecer relação entre os fatores ambientais e o uso racional dos recursos } \\
\text { naturais. }\end{array}$ \\
\hline & 10 & 19 & $\begin{array}{l}\text { Identificar os fatores de risco e modos de prevenção de acidentes, inclusive de } \\
\text { trânsito. }\end{array}$ \\
\hline & 11 & 20 & $\begin{array}{l}\text { Estabelecer relações entre poluição da água, do solo ou do ar com o equilíbrio } \\
\text { ecológico e com a qualidade de vida humana. }\end{array}$ \\
\hline & 12 & 27 & $\begin{array}{l}\text { Associar diferentes tipos de plantas com a utilização pelo ser humano como fontes } \\
\text { de remédios, madeira, papel e alimentos. }\end{array}$ \\
\hline & 13 & 28 & $\begin{array}{l}\text { Relacionar transformações no solo, na água, no ar e na diversidade dos seres vivos, } \\
\text { que ocorrem em conseqüência da ocupação do espaço terrestre pelo ser humano. }\end{array}$ \\
\hline & 14 & 29 & $\begin{array}{l}\text { Relacionar o fluxo de energia e as transformações da matéria nos diversos níveis } \\
\text { tróficos da cadeia alimentar. }\end{array}$ \\
\hline & 15 & 50 & $\begin{array}{l}\text { Agrupar organismos vertebrados (aves, mamíferos, répteis, anfíbios, peixes) de } \\
\text { acordo com as características de seu revestimento. (Saeb) }\end{array}$ \\
\hline & 16 & 60 & $\begin{array}{l}\text { Classificar materiais em miscíveis ou não em água em situações do cotidiano, } \\
\text { experimentais ou da natureza. (Saeb) }\end{array}$ \\
\hline \multirow{6}{*}{$\begin{array}{l}\text { III. } \\
\text { Funções } \\
\text { Vitais } \\
\text { dos Seres } \\
\text { Vivos }\end{array}$} & 17 & 9 & $\begin{array}{l}\text { Reconhecer a importância dos diferentes tipos de alimentos para o desenvolvimento } \\
\text { e a manutenção do corpo saudável. }\end{array}$ \\
\hline & 18 & 15 & Identificar as partes e/ou as funções do sistema excretor. \\
\hline & 19 & 22 & Associar as funções sensoriais com as relações entre o indivíduo e seu ambiente. \\
\hline & 20 & 24 & $\begin{array}{l}\text { Identificar as funções dos órgãos de reprodução e suas relações com os sistemas } \\
\text { nervoso e endócrino. }\end{array}$ \\
\hline & 21 & 25 & $\begin{array}{l}\text { Compreender as transformações biológicas e de comportamento ao longo das } \\
\text { diferentes fases da vida humana. }\end{array}$ \\
\hline & 22 & 26 & Identificar a função e/ou os componentes do aparelho circulatório. \\
\hline \multirow{10}{*}{$\begin{array}{l}\text { IV. Ser } \\
\text { Humano } \\
\text { e Saúde }\end{array}$} & 23 & 10 & Relacionar alimentação e atividade física com distúrbios nutricionais. \\
\hline & 24 & 11 & Reconhecer a importância da higiene bucal para a saúde. \\
\hline & 25 & 12 & Identificar as principais vias de transmissão de doenças infecciosas ou parasitárias. \\
\hline & 26 & 13 & $\begin{array}{l}\text { Estabelecer relação entre uso de produtos químicos (inseticidas, medicamentos, } \\
\text { poluentes, detergentes) e os riscos para a saúde. }\end{array}$ \\
\hline & 27 & 14 & Relacionar a qualidade do ar com a ocorrência de doenças. \\
\hline & 28 & 16 & Relacionar hábitos posturais a desvios de coluna e outros problemas de saúde. \\
\hline & 29 & 17 & $\begin{array}{l}\text { Identificar os cuidados necessários para prevenir e tratar doenças infecto- } \\
\text { contagiosas. }\end{array}$ \\
\hline & 30 & 18 & Reconhecer a importância da vacina na prevenção de doenças contagiosas. \\
\hline & 31 & 21 & Associar os efeitos do álcool e outras drogas à saúde e ao convívio social. \\
\hline & 32 & 23 & Identificar os riscos e conseqüências da atividade sexual sem prevenção. \\
\hline
\end{tabular}


Tabela 2 - Matriz de Competência 2000 - Ciências - $8^{\text {a }}$ Série

\begin{tabular}{|c|c|c|c|}
\hline ÁREA & \multicolumn{2}{|c|}{ DESCRITOR } & CONTEÚDO \\
\hline \multirow{4}{*}{$\begin{array}{l}\text { I. Terra e } \\
\text { Universo }\end{array}$} & 1 & 1 & Estabelecer relações entre fenômenos biológicos e fatores geofísicos. \\
\hline & 2 & 2 & Reconhecer as condições necessárias à existência e manutenção da vida no planeta. \\
\hline & 3 & 27 & Relacionar os efeitos da radiação solar à qualidade de vida humana. \\
\hline & 4 & 31 & Relacionar o intervalo de tempo de um dia com o movimento de rotação da Terra. \\
\hline \multirow{11}{*}{$\begin{array}{l}\text { II. Seres } \\
\text { Vivos, } \\
\text { Ambiente } \\
\text { e } \\
\text { Sociedade }\end{array}$} & 5 & 3 & $\begin{array}{l}\text { Reconhecer as interações entre os seres vivos e os elementos físico-químicos do } \\
\text { ambiente. }\end{array}$ \\
\hline & 6 & 4 & $\begin{array}{l}\text { Estabelecer relação entre os fatores ambientais e o uso racional dos recursos } \\
\text { ambientais. }\end{array}$ \\
\hline & 7 & 5 & $\begin{array}{l}\text { Analisar a relação entre geração, transformação e conservação de energia tendo em } \\
\text { vista as necessidades humanas. }\end{array}$ \\
\hline & 8 & 6 & $\begin{array}{l}\text { Relacionar o fluxo de energia e as transformações da matéria nos diversos níveis } \\
\text { tróficos da cadeia alimentar. }\end{array}$ \\
\hline & 9 & 8 & $\begin{array}{l}\text { Estabelecer relações entre a poluição da água, do solo ou do ar com o equilíbrio } \\
\text { ecológico e com a qualidade de vida. }\end{array}$ \\
\hline & 10 & 9 & $\begin{array}{l}\text { Analisar as responsabilidades, individual e coletiva, em relação ao equilíbrio } \\
\text { ambiental ou a saúde pública.. }\end{array}$ \\
\hline & 11 & 10 & $\begin{array}{l}\text { Relacionar as conseqüências do uso inadequado do solo e os riscos que representam } \\
\text { para a saúde ambiental e humana. }\end{array}$ \\
\hline & 12 & 23 & $\begin{array}{l}\text { Associar o desenvolvimento tecnológico aos diferentes processos de transformação } \\
\text { da energia. }\end{array}$ \\
\hline & 13 & 24 & Identificar as novas tecnologias que facilitam as atividades humanas. \\
\hline & 14 & 25 & $\begin{array}{l}\text { Relacionar as implicações dos avanços da bio-tecnologia à qualidade de vida } \\
\text { humana. }\end{array}$ \\
\hline & 15 & 30 & $\begin{array}{l}\text { Relacionar chuva ácida com a formação de ácido sulfúrico na atmosfera proveniente } \\
\text { da atividade industrial e/ou queima de combustíveis fósseis. }\end{array}$ \\
\hline \multirow{9}{*}{$\begin{array}{l}\text { III. } \\
\text { Funções } \\
\text { Vitais dos } \\
\text { Seres } \\
\text { Vivos }\end{array}$} & 16 & 7 & $\begin{array}{l}\text { Reconhecer a célula como unidade fundamental dos seres vivos, responsável pelas } \\
\text { funções vitais. }\end{array}$ \\
\hline & 17 & 11 & $\begin{array}{l}\text { Comparar as características comuns à espécie humana com as características que } \\
\text { variam nas populações. }\end{array}$ \\
\hline & 18 & 12 & $\begin{array}{l}\text { Reconhecer a importância dos diferentes tipos de alimentos para o desenvolvimento } \\
\text { e a manutenção do corpo saudável. }\end{array}$ \\
\hline & 19 & 13 & $\begin{array}{l}\text { Analisar a relação de interdependência dos diferentes aparelhos e sistemas que } \\
\text { compõem o corpo humano. }\end{array}$ \\
\hline & 20 & 14 & $\begin{array}{l}\text { Associar o papel dos componentes do sangue ao funcionamento e saúde do } \\
\text { organismo. }\end{array}$ \\
\hline & 21 & 15 & Identificar as partes e/ou as funções do sistema excretor. \\
\hline & 22 & 17 & $\begin{array}{l}\text { Compreender as transformações biológicas e de comportamento ocorridas ao longo } \\
\text { das diferentes fases da vida humana. }\end{array}$ \\
\hline & 23 & 29 & $\begin{array}{l}\text { Diferenciar, em situações do cotidiano, misturas e reações químicas, bem como no } \\
\text { preparo de alimentos. }\end{array}$ \\
\hline & 24 & 32 & Identificar a função e/ou os componentes do aparelho circulatório. \\
\hline \multirow{8}{*}{$\begin{array}{l}\text { IV. Ser } \\
\text { Humano } \\
\text { e Saúde }\end{array}$} & 25 & 16 & Associar os efeitos do álcool e outras drogas à saúde e ao convívio social. \\
\hline & 26 & 18 & Identificar as principais vias de transmissão de doenças infecciosas e parasitárias. \\
\hline & 27 & 19 & $\begin{array}{l}\text { Associar as conseqüências do uso de drogas e da atividade sexual sem segurança à } \\
\text { propagação da AIDS. }\end{array}$ \\
\hline & 28 & 20 & $\begin{array}{l}\text { Identificar os riscos e conseqüências da atividade sexual precoce e/ou sem } \\
\text { prevenção. }\end{array}$ \\
\hline & 29 & 21 & $\begin{array}{l}\text { Relacionar o uso inadequado de agrotóxicos com a saúde do trabalhador rural e a } \\
\text { contaminação do ambiente e dos alimentos. }\end{array}$ \\
\hline & 30 & 22 & $\begin{array}{l}\text { Estabelecer relação entre o uso de produtos químicos (inseticidas, medicamentos, } \\
\text { poluentes, detergentes) e os riscos para a saúde. }\end{array}$ \\
\hline & 31 & 26 & Associar a qualidade de vida ao não uso do tabaco. \\
\hline & 32 & 28 & $\begin{array}{l}\text { Associar o som como uma onda mecânica que se propaga no ar e provoca vibração } \\
\text { do tímpano, podendo levar à surdez. }\end{array}$ \\
\hline
\end{tabular}




\section{OS PARÂMETROS CURRICULARES NACIONAIS PARA CIÊNCIAS NATURAIS}

Em 1997-1998 a elaboração dos Parâmetros Curriculares Nacionais para o Ensino Fundamental pelo Ministério da Educação foi completada, os quais passaram a nortear o ensino público e privado em todo o país. Nos Parâmetros Curriculares para as Ciências Naturais, os objetivos eram ${ }^{1}$ concebidos para que o aluno desenvolvesse competências que lhe permitissem compreender o mundo e atuar como indivíduo e como cidadão, utilizando conhecimentos de natureza científica e tecnológica. Propunha-se que o ensino de ciências naturais se organizasse de forma que, ao final do Ensino Fundamental, os alunos apresentassem as seguintes capacidades:

- compreender a natureza como um todo dinâmico, sendo o ser humano parte integrante e agente de transformações do mundo em que vive;

- identificar relações entre conhecimento científico, produção de tecnologia e condições de vida, no mundo de hoje e em sua evolução histórica;

- formular questões, diagnosticar e propor soluções para problemas reais, a partir de elementos das ciências naturais, colocando em prática conceitos, procedimentos e atitudes desenvolvidos no aprendizado escolar;

- saber utilizar conceitos científicos básicos, associados a energia, matéria, transformação, espaço, tempo, sistema, equilíbrio e vida;

- saber combinar leituras, observações, experimentações, registros, etc., para coleta, organização, comunicação e discussão de fatos e informações;

- valorizar o trabalho em grupo, sendo capaz de ação crítica e cooperativa para a construção coletiva do conhecimento;

- compreender a saúde como bem individual e comum que deve ser promovido pela ação coletiva;

- compreender a tecnologia como meio para suprir necessidades humanas, distinguindo usos corretos e necessários daqueles prejudiciais ao equilíbrio da natureza e ao homem.

1 O verbo "ser" encontra-se no passado para os PCNs porque o governo estadual atual (gestão 2003-2006), declarou, em 2003, na pessoa de seu Secretário de Educação, num seminário em Curitiba, para mais de 2500 professores da Rede Pública Estadual que: "os PCNs estão definitivamente fora da agenda desse governo" (sic). 
Com relação aos conteúdos, deveriam ser organizados em blocos temáticos, de maneira que não fossem tratados como disciplinas ou tópicos isolados. Esses blocos apresentavam formas de abordagem e organização do conteúdo que possibilitavam flexibilidade na seqüência do trabalho, a abordagem de temas regionais e o estabelecimento de conexões com outras áreas e com os temas transversais.

Um primeiro referencial para os conteúdos eram os conceitos organizados em teorias científicas e conhecimentos tecnológicos. Para possibilitar a abordagem numa perspectiva interdisciplinar, tomou-se como segundo referencial os conceitos de energia, matéria, espaço, tempo, transformação, sistema, equilíbrio, variação, ciclo, fluxo, relação, interação e vida, pois eles estão presentes em diferentes campos do conhecimento e contribuem para conceituações gerais. Como terceiro referencial para os conteúdos, as apreciações intuitivas sobre a natureza e a tecnologia que interferem no aprendizado científico foram consideradas.

Os procedimentos eram as maneiras de obter, selecionar e elaborar o conhecimento, que podem ser explicitados em: observar, comparar, registrar, analisar, sintetizar, interpretar e comunicar. Quanto às atitudes, em ciências naturais, relacionavam-se ao desenvolvimento de posturas e valores humanos, na relação entre o homem, o conhecimento e o ambiente.

Os critérios para a seleção de conteúdos, de acordo com os objetivos gerais da área de ciências naturais e dos fundamentos dos Parâmetros Curriculares, apontavam que eles deveriam:

- se constituir em fatos, conceitos, procedimentos, atitudes e valores compatíveis com o nível de desenvolvimento intelectual do aluno, de maneira que ele possa operar com tais conteúdos e avançar efetivamente nos seus conhecimentos;

- favorecer a construção de uma visão de mundo, que se apresenta como um todo formado por elementos interrelacionados, entre os quais o homem, agente de transformação. $O$ ensino de ciências naturais deve relacionar fenômenos naturais e objetos da tecnologia, possibilitando a percepção de um mundo permanentemente reelaborado, estabelecendo-se relações entre o conhecido e o desconhecido, entre as partes e o todo;

- ser relevantes do ponto de vista social e ter revelados seus reflexos na cultura, para permitirem ao aluno compreender, em seu cotidiano, as relações entre o homem e a natureza mediadas pela tecnologia, superando interpretações ingênuas sobre a realidade à sua volta. Os temas transversais apontam conteúdos particularmente apropriados para isso. 
Os conteúdos eram distribuídos em blocos, ou eixos temáticos, para cada um dos quatro ciclos do Ensino Fundamental $\left(1^{\circ}\right.$ ciclo: $1^{\mathrm{a}}$ e $2^{\mathrm{a}}$ séries; $2^{\mathrm{O}}$ ciclo: $3^{\mathrm{a}}$ e $4^{\mathrm{a}}$ séries; $3^{\mathrm{o}}$ ciclo: $5^{\mathrm{a}}$ e $6^{\mathrm{a}}$ séries e $4^{\mathrm{o}}$ ciclo: $7^{\mathrm{a}}$ e $8^{\mathrm{a}}$ séries).

Os blocos temáticos para o $1^{\circ}$ e $2^{\circ}$ ciclos eram:

1. Ambiente

2. Ser Humano e Saúde

3. Recursos Tecnológicos

Para o $3^{\circ}$ e $4^{\circ}$ ciclos:

1. Vida e Ambiente

2. Ser Humano e Saúde

3. Tecnologia e Sociedade

4. Terra e Universo

Os objetivos e conteúdos estavam organizados nos PCNs de Ciências da Natureza, segundo estes blocos temáticos para cada um dos quatro ciclos. Também para cada um dos ciclos eram especificados os critérios de avaliação. Devem-se levar em conta também os "temas transversais" que, por seu interesse e caráter inter e transdisciplinar, deveriam ser retomados nas várias séries e disciplinas.

Observava-se que, no caso da matriz da AVA 97 para a $4^{\text {a }}$ série, os conteúdos de astronomia foram abordados dentro do eixo "Terra e Universo" que é válido, nos PCNs, apenas a partir do quarto ciclo $\left(7^{\mathrm{a}}\right.$ e $8^{\mathrm{a}}$ séries). As orientações curriculares, ou seja o Currículo de Ciências da SEED-PR de 1992 e os PCNs do MEC, certamente influíram, de modo diverso, nos resultados de cada uma das avaliações promovidas pela SEED, a partir de 1996.

Por exemplo, a inserção dos conteúdos de astronomia (a partir do currículo de 1992) encontrou as escolas despreparadas para aqueles conteúdos que nem sempre eram desenvolvidos. Para jogar um pouco mais de luz nessa questão, vale dizer que o currículo de 1992 transferiu os conteúdos de Geografia relacionados à astronomia para os conteúdos de Ciências. Isso gerou grande ansiedade nos professores de Ciências, que, despreparados (a imensa maioria graduada em Biologia, Pedagogia ou Licenciatura curta de Ciências), invariavelmente, alijavam o tema dos conteúdos gerais das ciências naturais.

A avaliação de 1996 foi muito confusa na definição dos objetivos do processo avaliativo: foram mais enfatizados os conteúdos relativos ao "corpo humano" e "tecnologia", já tradicionalmente valorizados no ensino de ciências. O conteúdo "noções de astronomia" foi interpretado como "astronáutica" e "telecomunicações". Os alunos avaliados nessas áreas, 
praticamente não abordadas nas escolas, responderam a partir de informações gerais, relativas a sua experiência de vida e a informações da imprensa, especialmente a televisão. Esse fato é corroborado pela comparação das respostas dos alunos do período noturno, em média mais velhos, com os alunos do diurno que tiveram pior desempenho nessas questões, ao contrário das questões de cunho mais "acadêmico".

Esperava-se que com os PCNs fosse feita uma seleção de conteúdos levada adiante pelos próprios professores da rede, além dos livros didáticos. Mas, pelos resultados obtidos, essa expectativa não foi atingida. A equipe que trabalhou na AVA, relativa à área de Ciências, buscou um quadro mais amplo para compreender o "fenômeno educativo" no Estado. Para tanto, como já relatado anteriormente, era necessário compreender a questão do livro didático na educação brasileira, como um todo.

\section{A QUESTÃO DO LIVRO DIDÁTICO}

Segundo o PNLD, estudos sobre a produção didática brasileira "vinham, reiteradamente, desde meados da década de 60, denunciando a falta de qualidade de parte significativa [dos] livros didáticos: seu caráter ideológico e discriminatório, sua desatualização, suas incorreções conceituais e suas insuficiências metodológicas". Esses livros, salienta o PNLD, muitas vezes de baixa qualidade, terminavam por constituir, para parte significativa da escola brasileira, o principal impresso utilizado por professores e alunos:

Seja em razão de uma inadequada formação de professores (inicial ou continuada), seja em razão de precárias condições de trabalho docente, seja, ainda, em razão das dificuldades enfrentadas para produzir e circular o livro no Brasil (particularmente para fazê-lo circular na escola), o livro didático brasileiro se converteu numa das poucas formas de documentação e consulta empregadas por professores e alunos.

Tornou-se, sobretudo, um dos principais fatores que influenciam o trabalho pedagógico, determinando sua finalidade, definindo o currículo, cristalizando abordagens metodológicas e quadros conceituais, organizando, enfim, o cotidiano da sala de aula. (Brasil, 2001, p.11-12) ${ }^{2}$

2 O livro didático, além do principal, tem sido o único impresso utilizado pelo professor (segundo depoimento dos próprios professores) na preparação de suas aulas, tornando-as meras repetições do que já está escrito no livro. 
A análise do PNLD 97 gerou uma classificação dos livros em quatro grandes categorias:

Excluídos - categoria composta de livros que apresentassem erros conceituais, indução a erros, desatualização, preconceitos ou discriminações de qualquer tipo.

Não recomendados - categoria constituída pelos manuais nos quais a dimensão conceitual se apresentasse com insuficiência, sendo encontradas impropriedades que comprometessem significativamente sua eficácia didático-pedagógica.

Recomendados com ressalvas - categoria composta por aqueles livros que possuíssem qualidades mínimas que justificassem sua recomendação, embora apresentassem, também, problemas que, entretanto, se levados em conta pelo professor, poderiam não comprometer sua eficáci.

Recomendados - categoria constituída por livros que cumprissem corretamente sua função, atendendo, satisfatoriamente, não só a todos os princípios comuns e específicos, como também aos critérios mais relevantes da área." (Brasil, 2001, p.13-14)

A partir desses estudos o PNLD adotou uma convenção gráfica para facilitar a visualização da categoria em que cada livro foi inserido:

*** Recomendados com distinção

** Recomendados

* Recomendados com ressalvas

\section{A análise do PNLD prossegue afirmando que}

no campo escolar, observam-se (...) impactos positivos [do PNLD]. Os dados mostram que, inicialmente, as escolhas dos professores recaíram, predominantemente, sobre livros menos qualificados pela avaliação. Progressivamente, contudo, os mais bem qualificados passaram a ser mais solicitados pelos docentes. (...) No que diz respeito aos livros de $1^{a}$ a $4^{a}$ séries, no $P N L D / 97$, as obras classificadas como não-recomendadas constituíram cerca de $72 \%$ do total de livros escolhidos. Esse total reduziu-se expressivamente no PNLD/98, constituindo aproximadamente $41 \%$ desse total; os recomendados (com distinção, simplesmente recomendados ou com ressalvas) passaram, conseqüentemente, a representar 59\% desse mesmo total (no PNLD/97, representaram apenas $28 \%$ ). (Brasil, 2001)

O PNLD/99 avaliou, pela primeira vez, os livros de $5^{\mathrm{a}}$ a $8^{\mathrm{a}}$ séries, que, por sua vez, só seriam analisados novamente no PNLD/2002. Além disso, a comparação com os dados do PNLD voltados para as primeiras séries do ensino fundamental é comprometida pela retirada da categoria não-recomendados. Apesar disso, é possível considerar - ao lado de outros fatores - "um impacto positivo dos resultados obtidos na avaliação dos livros de $1^{\mathrm{a}}$ a $4^{\mathrm{a}}$ séries sobre as escolhas docentes relativas aos de $5^{\mathrm{a}}$ a $8^{\mathrm{a}}$ ". (p.20-21). 
Em síntese, com livros de melhor qualidade nas escolas, o PNLD buscou (não se sabe se com ou sem sucesso, talvez seja necessário mais tempo para uma melhor avaliação):

- contribuir para um ensino de melhor qualidade: é uma referência consensual de qualidade para a produção de livros didáticos e para sua escolha, por professores;

- apresentar uma reformulação dos padrões do manual escolar brasileiro e criando condições adequadas para a renovação das práticas de ensino nas escolas. (Brasil, 2001, p.23)

No PNLD/98, embora a soma dos livros recomendados (com distinção, $21,88 \%$; com ressalvas, $22,15 \%$; ou simplesmente recomendados, $14,64 \%$ ) tenha constituído o grupo mais escolhido pelos docentes, a categoria que, isoladamente, se mostrou mais representada continuou a ser a dos nãorecomendados $(41,33 \%)$.

No PNLD/99, por fim, com a eliminação da categoria dos nãorecomendados, os docentes escolheram, predominantemente, os recomendados com ressalvas $(46,74 \%)$, e os recomendados com distinção representaram apenas $8,40 \%$ das escolhas. Os gráficos 1, 2 e 3 ilustram os percentuais dos livros escolhidos pelos professores de 1997 a 1999.

\section{Gráfico 1}

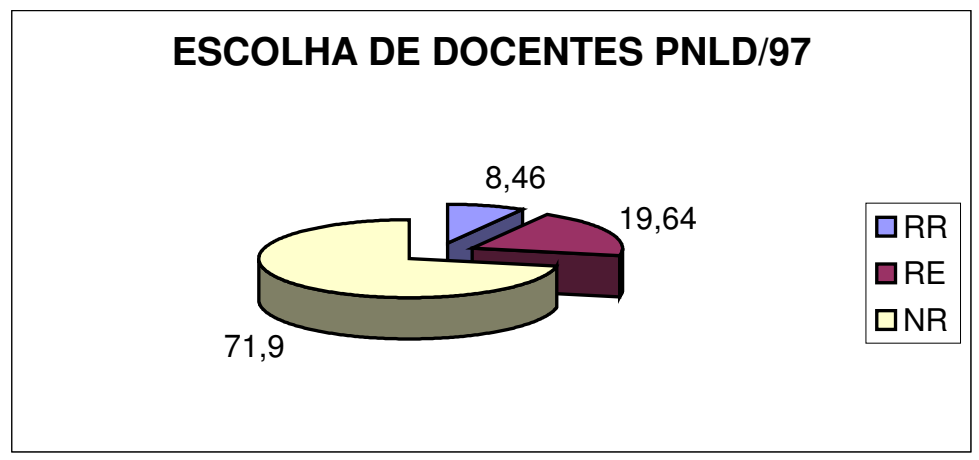

$\mathrm{RR}=$ recomendados com ressalvas; $\mathrm{RE}=$ recomendados; $\mathrm{NR}=$ não recomendados 


\section{Gráfico 2}

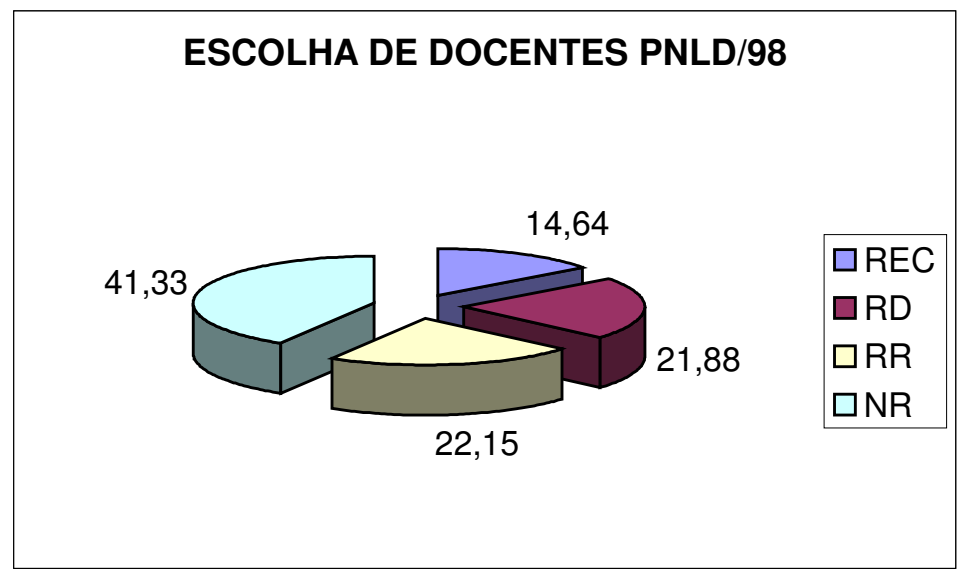

$\mathrm{REC}=$ recomendados; $\mathrm{RD}=$ recomendados com distinção; $\mathrm{RR}=$ recomendados com ressalvas; $\mathrm{NR}=$ não recomendados

\section{Gráfico 3}

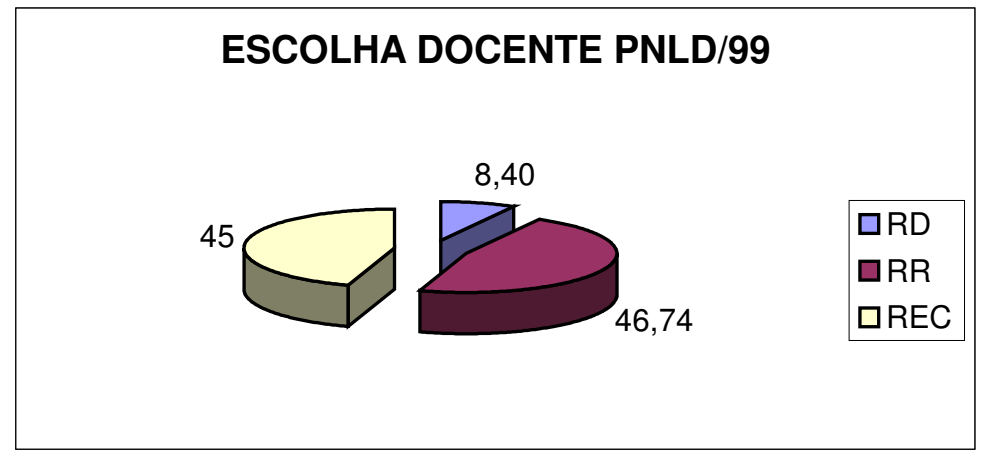

$\mathrm{RD}=$ recomendados com distinção; $\mathrm{RR}=$ recomendados com ressalvas; $\mathrm{REC}=$ recomendados

Além disso, inúmeros relatos de técnicos de secretarias estaduais vêm reportando, nos encontros nacionais do PNLD, dificuldades enfrentadas por muitos grupos de docentes no uso efetivo de livros recomendados e recomendados com distinção por eles escolhidos. Desse modo, "uma visão de conjunto da escolha do livro didático, assim como alguns dados relativos ao seu uso em sala de aula, apontam claramente para a 
formação docente como um dos fatores relevantes para a compreensão do referido descompasso" (Brasil, 2001, p.33).

Parece haver, dentro da análise do próprio PNLD, um consenso, expresso pela própria LDB, de que os cursos de magistério de nível médio são pouco apropriados para a formação de professores. Adicionalmente,

o modelo brasileiro para a formação de docentes em nível superior vem apresentando, tanto nas universidades quanto nas faculdades isoladas, sinais de esgotamento: se esse modelo foi adequado para formar quadros num momento de acentuada expansão quantitativa do sistema de ensino, vem se mostrando limitado para se inserir satisfatoriamente numa conjuntura em que a qualidade dos sistemas de ensino é o problema central. (Brasil, 2001)

Existe, ainda, dentro da mesma análise, o fenômeno da ampliação quantitativa do sistema de ensino brasileiro, que acabou por concentrar a formação de docentes em nível superior na rede privada de ensino.

O documento afirma que, de acordo com um estudo da Fundação Carlos Chagas, a formação dos docentes com nível superior na mesma amostra foi feita

pela maior parte dos(as) professores(as) em escolas particulares noturnas, provavelmente conciliando trabalho e estudo e que a questão da freqüência a cursos noturnos de ensino superior em escolas particulares deve ser olhada com atenção dado que os estudos disponíveis sobre a qualidade destes cursos mostram suas precárias condições de funcionamento e suas mais precárias condições de ensino. (Brasil, 2001)

Com efeito, de acordo com esses estudos, essas instituições apresentam os mais variados problemas: desde condições físicas inadequadas até volume insuficiente de recursos (advindos, fundamentalmente, de mensalidades pagas pelos alunos) e conseqüentemente baixa remuneração dos professores. Esses estudos evidenciam, também, que tendem a atuar, nessas escolas, docentes com formação insuficiente - predominam aqueles apenas graduados - e num regime de trabalho pouco adequado - prevalecem os docentes contratados como "aulistas".

Não se pode negar, portanto, que a escolha do livro didático pelos docentes vem apontando para a necessidade de as políticas públicas voltadas para a qualidade do ensino contemplarem adequadamente tanto a formação quanto o fortalecimento profissional do docente.

Com certeza, não está ao alcance do PNLD a resolução do conjunto de problemas que têm sua origem no descompasso entre suas expectativas 
e as dos professores. No entanto, o Programa "deve contribuir para a sua redução ..." (Brasil, 200, p. 34-35).

Pelo exposto, pode-se considerar que os livros didáticos adotados nas escolas devem ter tido grande influência sobre os resultados da AVA. Quando da sua implantação em 1996, os livros didáticos tradicionais não sofriam uma avaliação sistemática de sua qualidade, pois o programa de avaliação do livro didático, pelo MEC, teve início em 1997. A partir daí, eles começaram a ser analisados e avaliados, e os melhores passaram a ser recomendados. O projeto e os resultados do programa podem ser consultados na Internet ${ }^{3}$.

Existe uma enorme diversidade de livros de primeira à quarta série sendo que 66 deles são recomendados pelo MEC. Também estava disponível no site do MEC (até 2002) uma resenha de 26 desses livros, porém apenas de primeira série. Esses livros recebiam marcas gráficas de ** (1 livro), ** (10 livros) ou * (15 livros), conforme a atribuição de qualidade. Os professores utilizam essa fonte para fazer a escolha do livro a ser adotado em suas classes. Como chama a atenção o redator do texto, esses livros representam uma nova safra de material, e foram escritos para atender às orientações dos PCNs. Muitos deles são inéditos ou em primeira edição e estão sendo adotados apenas agora.

Portanto, os livros utilizados pelos alunos que sofreram as avaliações da SEED-PR eram, em sua maior parte, os livros mais antigos. Uma vez que essa produção bibliográfica certamente influenciou o processo de ensino e aprendizagem como um todo, e que não existiam parâmetros curriculares de referência, era de se esperar que nem sempre os conteúdos avaliados pela AVA estivessem contemplados no material didático. A própria qualidade dos livros era também variável. Este pode ser um dos fatores que condicionaram o desempenho dos alunos.

\section{ANÁLISE DO RELATÓRIO ESTATÍSTICO DA AVA 2000}

Os relatórios técnicos elaborados por Ignacio Cano (2001 e 2001a), referentes à AVA 2000, são bem mais ricos em informações de interesse pedagógico, envolvendo as influências socioeconômicas e estruturais, e permitindo análises mais conclusivas. Deve-se ressaltar que a realização de uma análise estatística multivariada, para determinar os fatores que possuem contribuição própria no desempenho dos estudantes, é uma ferramenta poderosa que permite conclusões mais corretas com respeito

3 Site do MEC: http://www.mec.gov.br, link "Ensino Fundamental", no "programa de avaliação do livro didático". 
aos aspectos sociais e pedagógicos envolvidos na avaliação. Para as análises, foram utilizados dados individuais dos alunos e dados referentes à suas escolas.

As características dos alunos foram obtidas do "questionário dos alunos", preenchido por eles no dia da prova, e as características das escolas foram coletadas no "questionário da escola", preenchido no dia da avaliação ou num período curto subseqüente. O questionário do aluno continha perguntas acerca de aspectos socioeconômicos, grupo familiar e nível de escolaridade dos pais; histórico escolar; leituras realizadas em casa; uso de computador; acompanhamento, pelos pais, da vida escolar; transporte escolar; trabalho; autopercepção como aluno e nível de aceitação da matéria, do professor e do livro didático. O questionário da escola incluía perguntas relativas à dependência administrativa, localização, turnos e modalidades de ensino ofertados, se possui turmas multisseriadas ou programas de correção de fluxo, organização dos ciclos, número de alunos, número de horas supridas em cada função dentro da escola, condições ambientais, equipamentos, atendimento oferecido aos alunos e problemas surgidos durante o curso. Além desses pontos, o questionário da escola contava com uma seção dedicada ao perfil do diretor; outra seção, dedicada à gestão escolar, contemplava perguntas sobre reuniões com pais e professores, atividades realizadas pelo diretor e adequação da proposta pedagógica. Nessa análise multivariada, Cano considerou uma significância de 0,01 , ou seja, um erro de no máximo $1 \%$ na afirmação de que uma variável ou relação é significativa.

Com os resultados da análise multivariada foi construído um modelo do desempenho em razão das características do aluno com as seguintes variáveis e resultados que merecem ser aqui comentados (Cano, 2001, 2001a):

1. nível de vida e nível de escolaridade dos pais são significativos no desempenho do estudante. Isto é, quanto maior os níveis de vida e de escolaridade do pai e da mãe melhor o desempenho do estudante na avaliação. A cada incremento de um desvio padrão na variável nível de vida resulta em 4,7 pontos na média da prova. Para cada nível educacional do pai (fundamental, médio e superior ) o aluno ganha 3,7 pontos na prova, e no caso da mãe 2,2 pontos; de forma que para os estudantes que possuem pai e mãe com nível superior a diferença a mais é de 18 pontos em relação ao aluno cujos pais têm pouca ou nenhuma escolaridade;

2. o trabalho e a reprovação também pesaram negativamente, de forma significativa, no desempenho. $\mathrm{O}$ aluno que trabalha perde 
5 pontos, e para cada reprovação (computadas até no máximo três) perde 8 pontos;

3. a participação em programa de correção de fluxo tem influência negativa significativa no desempenho, isto é, o desempenho é reduzido de forma significativa a cada ano de participação no programa. Cada ano que o aluno passa nesses programas (computados no máximo 2 anos) perde 12 pontos;

4. o atraso no ingresso do estudante no ensino fundamental é significativo no desempenho da $8^{\mathrm{a}}$ série, mas não o é na $4^{\mathrm{a}}$ série. Quanto maior o atraso no ingresso, em relação à idade padrão de 6-7 anos, pior o desempenho quando se faz a avaliação da $8^{a}$ série, mas este fator não influi na avaliação da $4^{\mathrm{a}}$ série. Para cada ano de atraso o aluno perde 7 pontos;

5. o número de escolas que o aluno freqüentou é significativo, pois quanto maior o número de escolas freqüentadas melhor o desempenho. Para cada escola que o aluno freqüentou (computadas no máximo 4 escolas) ele ganha 2 pontos;

6. os alunos que utilizam computador ganham 8 pontos em relação aos que não o usam;

7. quem "gosta mais ou menos" da matéria ganha 5,3 pontos e quem "gosta" ganha mais 5,3 pontos; portanto, a diferença de quem "gosta" para quem não gosta é de 10,6 pontos a mais.

Das variáveis não incluídas no modelo são significativas e devem merecer uma análise mais detalhada no futuro, tendo em vista a possível relação com a prática pedagógica do professor em sala de aula, a leitura e a orientação dos deveres em casa. É importante destacar o item 5 acima que afirma que o aluno apresenta um melhor desempenho em razão de um maior número de escolas freqüentadas. Esse fato faz supor que o desempenho dele melhora quando enfrenta situações novas, o que o prepararia para outra situação inédita: a prova. Desse modo, uma característica do aluno parece ser importante: sua experiência em enfrentar desafios.

Também com a análise multivariada foi construído um modelo do desempenho em função das características da escola. Apesar de a análise conjunta das características individuais e da escola se constituir em um terceiro passo, Cano incluiu aqui três variáveis de origem individual para evitar a influência delas no resultado final. As variáveis localização da escola (sede do município ou zona rural), organização dos ciclos (um ciclo de 4 séries, 2 ciclos de duas ou qualquer outro modelo) e a existência de ensino médio na escola não foram significativas. $\mathrm{O}$ número de horas 
supridas por funcionários, o atendimento a alunos e o tamanho da escola também não foram significativas. As variáveis da escola com algum impacto sobre o desempenho médio da escola na avaliação foram a existência de programas de correção de fluxo e a atividade à qual o diretor dedica a maior parte de seu tempo na gestão; esta última dicotomizada em democratização do processo de tomada de decisão e qualquer outra atividade.

Eliminando as diferenças relativas ao nível de vida e à escolaridade dos pais, as escolas onde programas de correção de fluxo foram implementados no ano anterior apresentam 1 ponto de desvantagem em relação àquelas que não o possuem; as que o implantaram em 2000 perdem 2 pontos e aquelas onde o programa existe há vários anos perdem 3 pontos.

Do modelo anterior pode-se ver que a diferença de desempenho entre o aluno que freqüenta o programa e o que não o freqüenta é muito maior do que entre a escola que possui o programa e a que não o possui.

As escolas onde o diretor dedica seu tempo preferencialmente à democratização da tomada de decisão apresentam uma vantagem de 2,4 pontos.

O modelo hierárquico do desempenho, em função das características do aluno e da escola, permite estudar, simultaneamente, em que medida ocorre o impacto das características do aluno na escola e viceversa, e foi elaborado com base nas análises anteriores e um número entre quinze e vinte mil alunos pertencentes a 1.112 escolas. É bom notar que houve ausência de informação em algumas variáveis, a existência de questionário de escolas sem provas de alunos e vice-versa, diminuindo a disponibilidade de dados para a análise.

A primeira análise é a da variância, sendo que a intra-escola das notas dos alunos é 1877,43 enquanto a interescolas é de 227,94, perfazendo uma variância total de 2105,37 . Isso significa que as diferenças entre os alunos (cerca de 90\%) é muito mais importante no desempenho do que as diferenças entre as escolas (cerca de $10 \%$ ).

O modelo final para ciências $-8^{\mathrm{a}}$ série - consegue explicar cerca de $24 \%$ da variância interescolas e cerca de $10 \%$ da variância intra-escolas. Deve-se registrar que, conforme o resultado citado anteriormente, as diferenças em relação aos alunos são muito maiores do que entre as escolas, sendo que os dados que se referem a eles são, ainda, mais imprecisos se comparados aos dados das escolas.

Com base nesses modelos, Cano propôs um modelo hierárquico que procurasse predizer, simultaneamente, o desempenho em função do aluno e da escola, cujos resultados mais relevantes são apresentados a seguir: 
1. Um incremento de um desvio padrão no índice de nível de vida acarreta um aumento médio de 3,65 pontos na prova. No entanto, se essa melhora no status socioeconômico acontece num ambiente em que as mães têm um alto nível de escolaridade, o efeito cresce muito. A cada grau de escolaridade média adicional das mães, o efeito sobe mais 3,84 pontos. Assim, numa escola cujas mães tenham um grau escolar adicional acima da média, um incremento de um desvio-padrão no nível de vida produz uma melhora de 7,49 pontos na prova $(3,65$ mais 3,84$)$. No caso de ciências $-8^{\text {a }}$ série - a incidência do nível de vida no desempenho é particularmente forte nos ambientes em que a escolaridade média das mães é alta.

2. A cada grau escolar a mais que a mãe possui, o aluno ganha, em média, 1,83 pontos.

3. Para cada ano que foi reprovado (no máximo 3) o aluno perde, em média, 8,7 pontos.

4. Para cada ano de atraso no ingresso da $1^{\text {a }}$ série (no máximo 2 anos), o aluno tem uma perda de 4,9 pontos.

5. Os alunos que trabalham têm uma desvantagem de 4,6 pontos em relação aos que não trabalham.

6. Quanto mais escolas o aluno freqüentou, melhor é o seu desempenho. Para cada escola adicional que freqüentou (no máximo 5) ele ganha 2 pontos.

7. Os usuários de computador estão 7,1 pontos na frente dos não usuários.

8. Quem "gosta da matéria" apresenta uma média superior em 6,6 pontos em relação a quem "gosta mais ou menos". Quem afirma "gostar mesmo" ganha outros 6,6 pontos.

9. Em ciências $-8^{a}$ série - os garotos estão 3,4 pontos na frente das garotas.

No modelo hierárquico, apenas uma variável escolar que tem origem na mensuração dos alunos apresentou impacto: o nível médio de todos os alunos da escola. Essa variável apresenta um efeito bem maior no conjunto da escola do que se considerada do ponto de vista individual do aluno. $\mathrm{O}$ aluno que aumenta individualmente o índice de nível de vida em uma unidade tem um aumento 3,7 pontos no desempenho. Por outro lado, quando há o incremento de uma unidade nesse mesmo índice para a média de todos os alunos da sua escola o aumento é de 10,7 pontos. Como as duas variáveis estão mensuradas na mesma escala, dado que na verdade são a mesma variável, seus coeficientes podem ser comparados diretamente. 
Isso indica que para o desempenho do aluno é mais importante ele estar numa escola onde o conjunto médio dos alunos tenha uma origem social mais favorável do que se encontrar, ele próprio, nessa categoria. É interessante notar que esse tipo de resultado é conhecido, de longa data, de outros levantamentos, o que serve para reforçar aqui a propriedade da análise estatística realizada.

Uma dessas pesquisas, com contribuição importante para o avanço da avaliação educacional, foi realizada nos Estados Unidos, resultando no Relatório Coleman, de 1966, que, entre outros aspectos, concluiu que as diferenças familiares, em particular o status socioeconômico da família do estudante, tinham influência maior do que a escola no desempenho dos testes aplicados. Esse tipo de pesquisa deu base, em parte nos EUA, para projetos de educação compensatória, como resposta política ao quadro de desigualdades educacionais verificado, projetos esses que, ao longo do tempo, se tornaram alvo de severas críticas (Forquim, 1995).

Na Grã-Bretanha também foram realizadas pesquisas - Relatório Crowter, em 1959 e Relatório Plowden, em 1969 - que enfatizaram em suas conclusões os aspectos socioeconômicos que influenciavam no desempenho educacional. Entre os desdobramentos na política educacional da GrãBretanha, decorrentes dessas pesquisas, está o prolongamento da escolaridade obrigatória (Forquim, 1995).

Deve-se, ainda, comentar o fato de não haver uma discussão no relatório com respeito à participação dos professores.

Cano afirma:

A princípio seria recomendável incluir no estudo também as características do professor, visto que existe um questionário para o professor. No entanto, não é possivel determinar no sistema atual quais professores correspondem a quais turmas. Em segundo lugar, o desempenho do aluno não poderia ser considerado fruto apenas do perfil do professor deste ano, mas do perfil de todos os professores, do seu histórico escolar, especialmente porque o teste não é um teste exclusivamente sobre a $8^{a}$ série, mas sobre as competências que o aluno deveria ter aprendido até a $8^{a}$ série. Em conseqüência, decidimos não incorporar este outro nível do professor na análise. (2001a)

Somos de opinião de que a inclusão dos professores em estudo futuro é de grande importância para o diagnóstico e o subsídio das ações de política educacional. Informações como o tipo e a área de qualificação, a participação em programas de capacitação em serviço, os métodos e as técnicas pedagógicas, dentre outras, permitiriam, se não correlacionar diretamente com o desempenho dos alunos, pela dificuldade apontada por Cano, pelo menos com o desempenho da escola, visto que os professores 
atuam, em geral, em várias séries; e se a pesquisa for feita com todos os professores de ciências da escola, e não apenas com os responsáveis pelas séries em exame, as informações poderiam dar subsídio a respeito do trabalho pedagógico em ciências na escola, ao longo do tempo.

O modelo hierárquico deve ser aperfeiçoado com a ampliação da avaliação educacional no Paraná e com a incorporação de outros indicadores que poderiam ser coletados no levantamento. Vale ressaltar a sua importância para subsidiar ações políticas visando ao desenvolvimento e à melhoria no âmbito educacional.

\section{ANÁLISE DO DESEMPENHO DOS ALUNOS 1996 - 2000}

A análise do processo avaliativo de 1996 a 2000 baseava-se numa grande quantidade de dados disponíveis envolvendo matrizes de referências (conteúdos), expectativa (percepção) dos professores quanto à possibilidade de acertos de seus alunos, aprovação/reprovação/abandono, e nos dados disponíveis em relação à política de livros didáticos (PNLD).

As tabelas 3 a 8, que apresentam a média de acertos em Ciências, entre os anos de 1996 e 2000, da $4^{\mathrm{a}}$ à $8^{\mathrm{a}}$ séries do ensino fundamental, mostram que ocorreu uma pequena mudança na média do percentual de acertos das questões. Porém, historicamente, essa média tem-se mantido próxima aos $50 \%$.

O curioso é cruzar essa informação com Língua Portuguesa e Matemática. As Ciências estão ligeiramente acima delas, o que equivale dizer que a proficiência nessas três áreas está intimamente ligada, uma vez que a área de Ciências não pode ser vista como uma linguagem isolada do mundo. Quando uma pessoa se alfabetiza, aprende a ler e a escrever numa linguagem que ela já fala. No caso da educação científica, a situação é diferente, visto que os aprendizes não falam, na grande maioria dos casos, qualquer linguagem científica. De uma só vez, eles devem aprender a pensar, falar, ler e escrever numa outra linguagem, que traz consigo uma maneira particular de ver o mundo.

Cobern (1996) refere-se a esse fenômeno como uma espécie de apartheid cognitivo, onde o aprendiz cria um compartimento para os conceitos científicos incompatíveis com a orientação geral de sua visão de mundo, deixando-os à mão para que possam ser consultados em ocasiões especiais, tal como nos dias de avaliação, mas eles não têm efeito algum sobre sua vida cotidiana e seu modo de pensar. Enquanto ele está sob pressão, esses conceitos sustentam um significado próximo àquele que existe no discurso científico, ou seja, as paredes do compartimento 
cognitivo são mantidas no lugar. No entanto, assim que a pressão é aliviada, as paredes se rompem e os conceitos científicos ou são eliminados, ou são ressignificados de maneira que se tornam consistentes com a visão de mundo, ainda que estejam distanciados de seu significado original no discurso científico.

Tabela 3 - Média de acertos, escores máximo e mínimo dos alunos da $8^{\text {a }}$ série, em ciências, por rede de ensino e turno - Paraná, 1996

\begin{tabular}{l|c|c|c|c|c|c}
\hline \multirow{2}{*}{ Rede } & \multicolumn{2}{|c|}{ Estadual } & \multicolumn{2}{c|}{ Municipal } & \multicolumn{2}{c}{ Particular } \\
\cline { 2 - 7 } & Diurno & Noturno & Diurno & Noturno & Diurno & Noturno \\
\hline $\begin{array}{l}\text { Média de acertos } \\
(\%)\end{array}$ & 45,6 & 48,6 & 44,7 & 58,4 & 51,7 & - \\
\hline
\end{tabular}

Fonte: SEED/PQE/GAC.

Tabela 4 - Média de acertos, escores máximo e mínimo dos alunos da $8^{\mathrm{a}}$ série, em ciências, por turno e dependência administrativa Paraná, 1997

\begin{tabular}{c|c|c|c|c|c|c|c|c|c}
\hline \multirow{2}{*}{ Rede } & \multicolumn{3}{|c|}{ Estadual } & \multicolumn{3}{c|}{ Municipal } & \multicolumn{3}{c}{ Particular } \\
\cline { 2 - 10 } Estatística & $\mathrm{M}$ & $\mathrm{T}$ & $\mathrm{N}$ & $\mathrm{M}$ & $\mathrm{T}$ & $\mathrm{N}$ & $\mathrm{M}$ & $\mathrm{T}$ & $\mathrm{N}$ \\
\hline Média de acertos (\%) & 41,6 & 40,7 & 38,0 & 40,7 & 39,8 & 39,5 & 52,9 & - & - \\
\hline
\end{tabular}

Fonte: SEED/PQE/GAC.

Tabela 5 - Média de acertos em ciências e números de alunos da $8^{\text {a }}$ série por turno - Paraná, 1998

\begin{tabular}{l|c|c|c|c}
\hline \multicolumn{1}{c|}{ Estatística } & $\mathrm{M}$ & $\mathrm{T}$ & $\mathrm{N}$ & Total do Estado \\
\hline Média de acertos das questões & 20,50 & 22,71 & 21,94 & - \\
\hline Média de acertos (\%) & 45,60 & 50,50 & 48,80 & 50,20 \\
\hline Número de alunos & 79.019 & 29.947 & 68.036 & 177.002 \\
\hline
\end{tabular}

Fonte: SEED/PQE/GAC. 
Tabela 6 - Média de acertos, escores máximo e mínimo dos alunos da $4^{\mathrm{a}}$ série, em ciências, por turno e dependência administrativa Paraná, 1997

\begin{tabular}{c|c|c|c|c|c|c}
\hline \multirow{2}{*}{ Estatística } & \multicolumn{2}{|c|}{ Estadual } & \multicolumn{2}{c|}{ Municipal } & \multicolumn{2}{c}{ Particular } \\
\cline { 2 - 7 } & $\mathrm{M}$ & $\mathrm{T}$ & $\mathrm{M}$ & $\mathrm{T}$ & $\mathrm{M}$ & $\mathrm{T}$ \\
\hline Média de acertos (\%) & 53,2 & 54,1 & 53,9 & 53,9 & 57,4 & 62,5 \\
\hline
\end{tabular}

Fonte: SEED/PQE/GAC.

Tabela 7 - Média de acertos, escores máximo e mínimo dos alunos da $4^{\mathrm{a}}$ série, em ciências, por turno e dependência administrativa Paraná, 1998

\begin{tabular}{l|c|c|c|c}
\hline \multirow{2}{*}{ Estatística } & \multicolumn{2}{|c|}{ Estadual } & \multicolumn{2}{c}{ Municipal } \\
\cline { 2 - 5 } & $\mathrm{M}$ & $\mathrm{T}$ & $\mathrm{M}$ & $\mathrm{T}$ \\
\hline Média de acertos (\%) & 54,6 & 56,1 & 53,0 & 54,7 \\
\hline
\end{tabular}

Fonte: SEED/PQE/GAC.

Tabela 8 - Quadro geral da avaliação do rendimento escolar para a $4^{\mathrm{a}} \mathrm{e}$ a $8^{\text {a }}$ séries

\begin{tabular}{l|c|c|c}
\hline \multicolumn{1}{c|}{ Área de Conhecimento } & $\begin{array}{c}\text { Nível } \\
\text { Séries }\end{array}$ & $\begin{array}{c}\text { Média } \\
\text { (Nível de desempenho) }\end{array}$ & $\begin{array}{c}\text { Alunos } \\
\text { Avaliados }\end{array}$ \\
\hline \multirow{2}{*}{ Ciências } & $4^{\mathrm{a}}$ & 250 & 38.033 \\
\cline { 2 - 4 } & $8^{\mathrm{a}}$ & 250 & 31.125 \\
\hline \multirow{2}{*}{ Língua Portuguesa } & $4^{\mathrm{a}}$ & 250 & 39.239 \\
\cline { 2 - 4 } & $8^{\mathrm{a}}$ & 250 & 31.125 \\
\hline \multirow{2}{*}{ Matemática } & $4^{\mathrm{a}}$ & 250 & 38.441 \\
\cline { 2 - 4 } & $8^{\mathrm{a}}$ & 250 & 31.007 \\
\hline
\end{tabular}

Fonte: SEED/CIE -AVA 2000.

Níveis de desempenho: NÍVEL I - média abaixo de 225; NÍVEL II - média entre 225 e abaixo de 250; NÍVEL III - média entre 250 e abaixo de 275; NÍVEL IV - média igual ou acima de 275.

Os resultados da AVA 2000 usaram uma escala de proficiência diferente daquela usada nas avaliações anteriores (como mostra a tabela 9). No entanto, os resultados mostram que, em Ciências, os estudantes localizam-se na fronteira Nível II - Nível III, ou seja: conhecimentos muito 
gerais sobre os conteúdos e reconhecimento parcial de relações de causa e efeito.

Tabela 9 - Valores referenciais de desempenho ${ }^{4}$

\begin{tabular}{c|c|c|c|c}
\hline \multicolumn{2}{c|}{ Desempenho inferior } & Desempenho médio & \multicolumn{2}{c}{ Desempenho superior } \\
\hline 200 & 225 & 250 & 275 & 300 \\
\hline
\end{tabular}

Os resultados demonstraram o complexo processo de ensino e aprendizagem e das políticas públicas de ensino, que os inserem naquilo que Cobern (1996) batizou de apartheid cognitivo. Para se ter uma idéia desse processo mais geral, os resultados para Língua Portuguesa e Matemática são mostrados na tabela 10.

Tabela 10 - Índices de proficiência médio para escolas estaduais e municipais

\begin{tabular}{c|c|c}
\hline Proficiência & Escola Estadual & Escola Municipal \\
\hline $\begin{array}{c}\text { Língua Portuguesa } \\
4^{a} \text { série }\end{array}$ & 258,43 & 248,13 \\
\hline $\begin{array}{c}\text { Língua Portuguesa } \\
8^{\text {a } \text { série }}\end{array}$ & 249,62 & 254,82 \\
\hline $\begin{array}{c}\text { Matemática } \\
4^{a} \text { série }\end{array}$ & 260,06 & 247,90 \\
\hline $\begin{array}{c}\text { Matemática } \\
8^{a} \text { série }\end{array}$ & 249,89 & 255,57 \\
\hline
\end{tabular}

Fonte: SEED/AVA 2000.

A tabela 11 apresenta os conteúdos dos Parâmetros Curriculares Nacionais, inerentes ao processo de Avaliação 1998, e a média de acertos (de 0 a $100 \%$ ).

\footnotetext{
4 Os valores inferiores ao valor médio $(=250)$, representam conteúdos não aprendidos, em seu valor mais baixo, ou em fase inicial de aprendizagem (quando o percentual de acerto da avaliação fica entre $50,1 \%$ a $64,9 \%$ ), e valores superiores a 250 , em fase adiantada de aprendizagem (índice de acerto entre 65,0 e 79,9\%) ou de aprendizagem total (índice igual ou superior a $80,0 \%$ ).
} 


\section{Tabela 11 - Média de acertos de agrupamentos de objetivos, das escolas}

estaduais - Paraná, 1998

\begin{tabular}{|c|c|c|}
\hline CONTEÚDO & OBJETIVOS & $\begin{array}{c}\text { MÉDIA } \\
\text { de } \\
\text { acertos } \\
(\%) \\
\end{array}$ \\
\hline Astronomia & 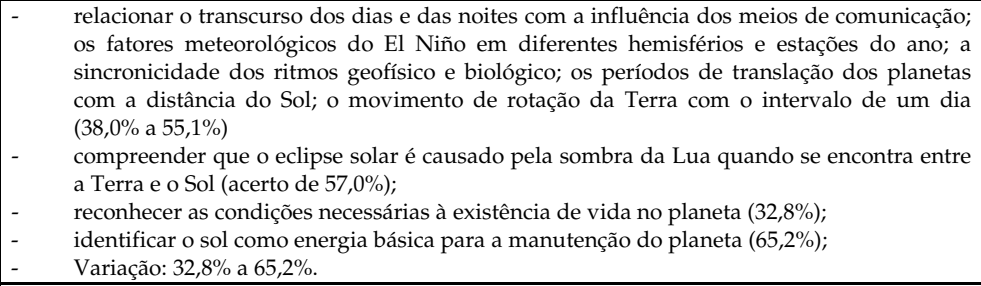 & 48,8 \\
\hline $\begin{array}{l}\text { Ambiente e } \\
\text { Cidadania }\end{array}$ & $\begin{array}{l}\text { - } \quad \text { reconhecer a água como necessidade biológica, utilidade e custos; as condições de vida } \\
\text { com a degradação ambiental; a geração de energia à transformação e conservação pelo ser } \\
\text { humano ( } 32,4 \% \text { a } 67,1 \%) \text {; } \\
\text { compreender a interação dos elementos físico-químicos pelo ciclo dos materiais e fluxo de } \\
\text { energia; que a energia armazenada nas substâncias orgânicas e que servem de alimentos } \\
\text { ou combustíveis tem origem na energia presente na fotossíntese }(28,3 \text { a } 43,7 \%) ; \\
\text { - } \quad \text { reconhecer a responsabilidade do homem sobre o equilíbrio/desequilíbro ambiental e } \\
\text { que as substâncias dos vegetais se transferem indiretamente para os seres vivos ( } 32,4 \% \text { a } \\
48,0 \%) \\
\text { identificar os riscos para a saúde ambiental e humana em relação às formas inadequadas } \\
\text { com que o homem ocupa no solo }(37,5 \%) ; \\
\text { variação: } 28,3 \% \text { a } 67,1 \% \text {. }\end{array}$ & 43,2 \\
\hline $\begin{array}{l}\text { Corpo } \\
\text { Humano }\end{array}$ & 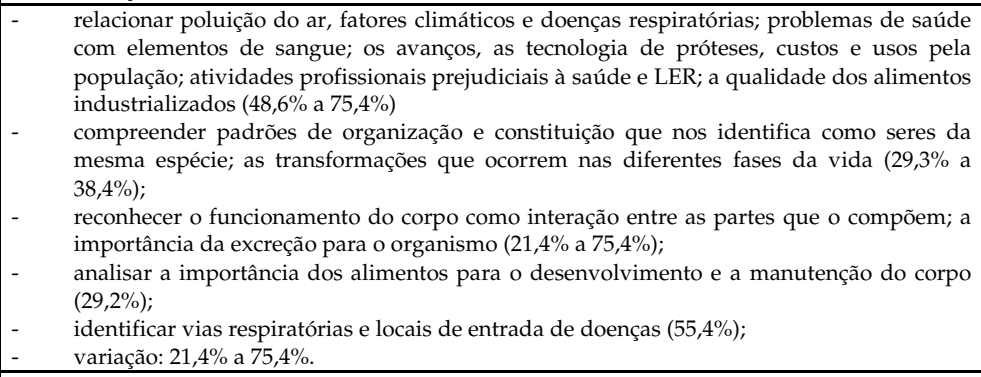 & 45,3 \\
\hline $\begin{array}{l}\text { Saúde e } \\
\text { Cidadania }\end{array}$ & 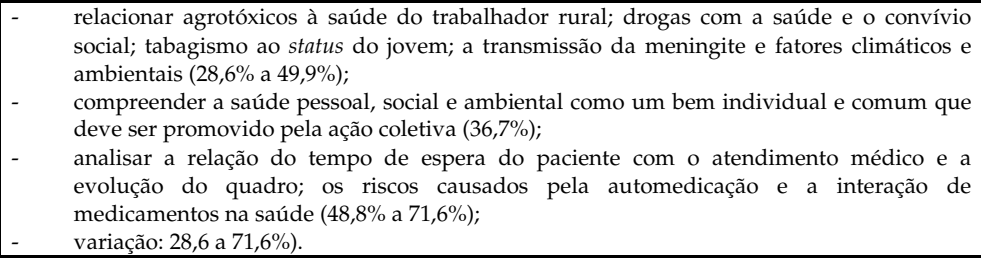 & 46,3 \\
\hline $\begin{array}{l}\text { Reprodução e } \\
\text { Sexualidade }\end{array}$ & $\begin{array}{ll}\text { - } & \text { relacionar gravidez precoce ao aborto e a conseqüência das atividades sexuais sem } \\
\text { segurança; mudanças culturais nos hábitos sexuais a novas tecnologias de medicamentos } \\
(43,2 \% \text { a } 53,0 \%) ; \\
\text { - } \quad \text { analisar os aumentos de casos de Aids através de gráficos }(43,0 \%) ; \\
\text { variação: } 43,0 \text { a } 53,0 \% \text {. }\end{array}$ & 46,7 \\
\hline $\begin{array}{l}\text { Terra e } \\
\text { Ambiente }\end{array}$ & $\begin{array}{l}\text { - } \quad \text { relacionar chuva ácida com ácido sulfúrico pela presença do enxofre e as conseqüências } \\
\text { da queima de combustíveis fósseis ( } 50,3 \%) ; \\
\text { - } \quad \text { reconhecer padrões de funcionamento das partes da planta (raiz, caule, etc.) }(57,8 \%) ; \\
\text { - compreender o som como onda mecânica, a propagação no ar e a vibração no tímpano; a } \\
\text { transformação de energia cinética em energia elétrica nas usinas hidroelétricas ( } 27,8 \% \text { a } \\
30,0 \%) ; \\
\text { diferenciar misturas e reações químicas em situações do cotidiano }(39,2 \%) ; \\
\text { - } \quad \text { identificar os diferentes tipos de solo a partir de experiências e relatos de observação } \\
(52,0 \%) ; \\
\text { variação: } 27,8 \% \text { a } 57,8 \% \text {. }\end{array}$ & 42,9 \\
\hline
\end{tabular}


Além de todo o problema inerente ao processo de ensino e aprendizagem, devemos entender a dinâmica que envolve a aprovação, reprovação e o abandono, a formação docente, os currículos escolares, e a questão da qualidade dos cursos de formação e do material didático (livros, bibliotecas escolares, recursos audiovisuais) disponível na escola. As tabelas 12 e 13 apresentam, com base no último Censo Escolar, os dados de aprovação, reprovação e abandono e a formação dos professores.

É interessante, no intercruzamento de vários dados, analisar os resultados da percepção dos professores com respeito à expectativa da média de acertos para as questões constantes na Avaliação 96/97. Aqui temos uma amostragem significativa que indica um distanciamento entre a educação dada e aquela pretendida. Há um hiato imenso entre ensino e aprendizagem, que revela que as ações de políticas públicas de ensino devem ser plurais e paralelas, envolvendo desde a educação continuada de professores até o aparelhamento de escolas e a escolha de livros didáticos de qualidade.

Tabela 12 - Taxas de aprovação, reprovação e abandono

\begin{tabular}{l|c|c|c}
\hline & ${\text { Ensino de } 1^{\mathrm{a}} \text { a } 4^{\mathrm{a}}}$ & ${\text { Ensino de } 5^{\mathrm{a}} \text { a } 8^{\mathrm{a}}}$ & Ensino Médio \\
\hline Alunos & 833.412 & 727.025 & 415.483 \\
\hline $\begin{array}{l}\text { Número médio de } \\
\text { alunos por turma }\end{array}$ & 27 & 34 & 37 \\
\hline Aprovação (\%) & 88 & 82 & 76 \\
\hline Reprovação (\%) & 10 & 11 & 10 \\
\hline Abandono (\%) & 2 & 7 & 14 \\
\hline
\end{tabular}

Fonte: MEC/INEP/SEEC - Censo Escolar 2001 (Resultados Preliminares)

Tabela 13 - Número e formação dos professores

\begin{tabular}{l|c|c|c}
\hline & Ensino de $1^{\mathrm{a}}$ a $4^{\mathrm{a}}$ & Ensino de $5^{\mathrm{a}}$ a $8^{\mathrm{a}}$ & Ensino Médio \\
\hline Professores & 38.803 & 35.817 & 22.652 \\
\hline $\begin{array}{l}\text { Professores com } \\
\text { nível superior (\%) }\end{array}$ & 43 & 97 & 98 \\
\hline
\end{tabular}

Fonte: MEC/INEP/SEEC - Censo Escolar 2001 (Resultados Preliminares) 


\section{PERCEPÇÃO DOS PROFESSORES - AVA 1996}

No relatório da AVA 1996 há um levantamento interessante que trata da expectativa dos professores quanto ao desempenho dos estudantes avaliados. Esse levantamento se deu com base em dois tópicos, apresentados a seguir:

1. Que porcentagem dos seus alunos você acha que responderá corretamente essa questão sem adivinhar a resposta?
(a) Praticamente nenhum aluno.
(b) Entre 10 e $40 \%$ dos alunos.
(c) Entre 41 e $60 \%$ dos alunos.
(d) De 61 a $90 \%$ dos alunos.
(e) Praticamente todos os alunos.

2. Durante este ano escolar você ensinou o conteúdo necessário para seus alunos responderem esta questão corretamente?
(a) Sim.
(b) Não, porque já havia sido ensinado em séries anteriores a esta.
(c) Não, porque será ensinado em séries posteriores a esta.
(d) Não, porque não considero este conteúdo importante.
(e) Não, porque não houve tempo.

Os dados demonstram que a maioria dos professores diz ter ensinado os conteúdos ora contemplados, conforme respostas fornecidas à pergunta número 2 do questionário do professor no dia da AVA 1996.

Verifica-se divergência entre os percentuais apontados pelos professores, ao avaliar seus alunos, e o percentual real de acertos apresentado pelos alunos. Essa diferença foi mais acentuada na $4^{a}$ série e em todas as disciplinas. Observa-se que a alternativa " $\mathrm{A}$ " do questionário do professor apresenta os percentuais mais altos, demonstrando, assim, certa incoerência entre o desempenho apresentado, não havendo correspondência entre o que o professor declara ter ensinado e o que o aluno demonstrou ter aprendido. 
Tabela 14 - Percentual de respostas dos professores a respeito do conteúdo de ciências trabalhado na $4^{a}$ série e percentual de acerto dos alunos - Paraná, 1996. Média de percentual da expectativa do professor dentro da faixa de acerto do aluno $=28,92 \%$

\begin{tabular}{|c|c|c|c|c|c|c|c|}
\hline \multirow[b]{2}{*}{ Questão } & \multirow[b]{2}{*}{ Conteúdos } & \multicolumn{5}{|c|}{ Avaliação do Professor } & \multirow{2}{*}{$\begin{array}{l}\text { Acerto } \\
\text { dos } \\
\text { alunos }\end{array}$} \\
\hline & & $\mathbf{A}$ & B & $\mathrm{C}$ & D & $\mathrm{E}$ & \\
\hline \multicolumn{8}{|c|}{ Até $50 \%$ de Acerto } \\
\hline 1 & Estações do ano e movimento da Terra & 91,2 & 5,3 & 0,6 & 0,6 & 2,4 & 31,1 \\
\hline 2 & Fases da Lua & 71,8 & 9,4 & 11,2 & 0,6 & 7,1 & 13,4 \\
\hline 4 & Homem e aumento da poluição & 93,5 & 2,4 & 0,6 & 0,6 & 2,9 & 30,3 \\
\hline 9 & $\begin{array}{l}\begin{array}{l}\text { Interdependência entre elementos e } \\
\text { biosfera }\end{array} \\
\text { e }\end{array}$ & 84,1 & 4,1 & 7,1 & 0,0 & 4,7 & 21,6 \\
\hline 16 & Função dos órgãos excretores & 74,7 & 2,9 & 9,4 & 0,0 & 12,4 & 30,7 \\
\hline 21 & Função do sistema nervoso & 66,5 & 0,6 & 7,6 & 0,0 & 14,7 & 26,4 \\
\hline 23 & Diferença entre soro e vacina & 68,8 & 2,4 & 2,9 & 0,0 & 15,9 & 33,7 \\
\hline 3 & $\begin{array}{l}\text { Hábitos alimentares e movimento da } \\
\text { Terra }\end{array}$ & 69,4 & 6,5 & 8,2 & 6,5 & 8,8 & 49,5 \\
\hline 6 & Função do aparelho circulatório & 93,5 & 0,6 & 1,2 & 0,0 & 4,7 & 40,5 \\
\hline 20 & $\begin{array}{l}\begin{array}{l}\text { Órgãos reprodutivos } \\
\text { feminino }\end{array}\end{array}$ & 78,2 & 0,6 & 2,9 & 0,0 & 17,6 & 47,5 \\
\hline 10 & Água e seres vivos & 95,3 & 0,6 & 1,8 & 0,0 & 2,4 & 41,5 \\
\hline 25 & $\begin{array}{l}\begin{array}{l}\text { Aleitamento materno } \\
\text { materna }\end{array} \\
\text { e imunização }\end{array}$ & 81,8 & 0,6 & 2,4 & 2,4 & 0,0 & 46,7 \\
\hline 26 & Importância da vacinação & 60,6 & 4,7 & 5,3 & 0,6 & 18,8 & 48,2 \\
\hline \multicolumn{8}{|c|}{ Entre $50 \%$ e $65 \%$ de Acerto } \\
\hline 8 & Sol e existência da vida na Terra & 90,6 & 2,4 & 3,5 & 0,6 & 2,9 & 59,3 \\
\hline 17 & Posição da Terra no sistema solar & 92,4 & 2,4 & 1,8 & 0,0 & 3,5 & 51,3 \\
\hline 18 & Eliminação de resíduos (excreção) & 91,2 & 1,2 & 4,1 & 0,0 & 3,5 & 50,9 \\
\hline 22 & Higiene e órgãos genitais & 79,4 & 0,6 & 2,9 & 1,2 & 5,9 & 61,8 \\
\hline 24 & Hábitos posturais e desvios de coluna & 82,4 & 2,4 & 1,2 & 0,0 & 4,1 & 64,7 \\
\hline 27 & Órgãos dos sentidos e ambiente & 86,5 & 1,2 & 0,0 & 0,0 & 2,4 & 64,3 \\
\hline 28 & Prevenção contra a Aids & 83,5 & 0,0 & 2,4 & 0,0 & 4,1 & 59,3 \\
\hline \multicolumn{8}{|c|}{ Mais de $65 \%$ de Acerto } \\
\hline 5 & $\begin{array}{llll}\begin{array}{l}\text { Doenças } \\
\text { insalubre }\end{array} & \text { respiratórias } & \text { e } & \text { ambiente } \\
\end{array}$ & 98,2 & 1,2 & 0,0 & 0,0 & 0,6 & 66,6 \\
\hline 7 & $\begin{array}{l}\text { Alimentação inadequada e doenças } \\
\text { cardíacas }\end{array}$ & 80,6 & 1,2 & 10,0 & 0,0 & 8,2 & 74,6 \\
\hline 11 & Causa de subnutrição & 95,9 & 1,8 & 0,6 & 0,0 & 1,8 & 76,8 \\
\hline 12 & Alimentação e higiene & 96,5 & 0,6 & 0,6 & 0,0 & 2,4 & 82,5 \\
\hline 13 & Prevenção à cárie & 94,7 & 1,2 & 0,6 & 0,0 & 3,5 & 78,0 \\
\hline 14 & Saneamento básico & 94,7 & 1,8 & 0,6 & 0,0 & 2,9 & 73,2 \\
\hline 15 & Degradação ambiental e os seres vivos & 94,7 & 1,8 & 1,2 & 0,6 & 2,4 & 73,1 \\
\hline 19 & Sistemas de locomoção & 92,4 & 0,6 & 2,9 & 0,6 & 2,9 & 66,1 \\
\hline 29 & Efeito das drogas e a saúde & 79,4 & 0,6 & 2,4 & 0,0 & 7,6 & 79,1 \\
\hline 30 & Drogas e comportamento social & 81,8 & 0,0 & 2,9 & 0,0 & 4,7 & 80,4 \\
\hline
\end{tabular}


Tabela 15 - Percentual de respostas dos professores a respeito do conteúdo de ciências trabalhado na $8^{\mathrm{a}}$ série e percentual de acerto dos alunos - Paraná, 1996. Média de percentual da expectativa do professor dentro da faixa de acerto do aluno $=31,02 \%$

\begin{tabular}{|c|c|c|c|c|c|c|c|}
\hline \multirow[b]{2}{*}{ Questão } & \multirow[b]{2}{*}{ Conteúdos } & \multicolumn{5}{|c|}{ Avaliação do Professor } & \multirow{2}{*}{$\begin{array}{l}\text { Acerto } \\
\text { dos } \\
\text { alunos }\end{array}$} \\
\hline & & $\mathbf{A}$ & B & $\mathrm{C}$ & D & $\mathrm{E}$ & \\
\hline \multicolumn{8}{|c|}{ Até 50\% de Acerto } \\
\hline 13 & Qualidade do ar e doenças respiratórias & 58,6 & 25,0 & 4,3 & 0,0 & 11,3 & 12,6 \\
\hline 4 & Estruturas celulares e funções & 82,7 & 9,9 & 3,4 & 0,2 & 3,6 & 14,5 \\
\hline 12 & Efeito do cigarro para a saúde & 64,2 & 11,7 & 5,4 & 0,0 & 18,2 & 17,0 \\
\hline 8 & Importância do núcleo na clonagem & 48,2 & 5,6 & 15,3 & 0,9 & 29,3 & 18,5 \\
\hline 16 & Caminho do sangue no corpo humano & 81,3 & 7,4 & 1,6 & 0,2 & 8,8 & 22,8 \\
\hline 9 & Importância dos alimentos & 66,2 & 10,6 & 6,3 & 1,6 & 14,4 & 24,7 \\
\hline 10 & Hábitos de higiene / parasitose intestinal & 51,4 & 39,6 & 1,6 & 0,7 & 6,3 & 26,9 \\
\hline 27 & Educação sexual e qualidade de vida & 50,0 & 7,2 & 2,7 & 1,1 & 21,2 & 28,2 \\
\hline 30 & Ação do homem sobre a natureza & 32,9 & 30,0 & 4,3 & 0,7 & 13,5 & 31,2 \\
\hline 28 & Experiências genéticas e seus aspectos & 30,6 & 6,1 & 10,6 & 0,2 & 34,7 & 33,9 \\
\hline 29 & Acesso do homem e avanços da ciência & 42,3 & 16,2 & 5,2 & 1,6 & 16,7 & 33,9 \\
\hline 23 & Receptores sensoriais e estímulos & 58,6 & 25,0 & 4,3 & 0,0 & 11,3 & 37,8 \\
\hline 21 & Efeitos das drogas no organismo & 55,0 & 9,2 & 1,6 & 0,2 & 16,7 & 38,3 \\
\hline 22 & Influência dos hormônios no organismo & 54,5 & 7,0 & 2,3 & 0,2 & 18,9 & 39,2 \\
\hline 3 & Vida e degradação ambiental & 41,0 & 52,0 & 2,5 & 0,2 & 4,1 & 39,9 \\
\hline 2 & Efeitos da radiação solar & 43,2 & 49,5 & 2,3 & 0,0 & 4,3 & 40,4 \\
\hline 19 & Implicações éticas dos transplantes & 66,2 & 10,6 & 6,3 & 1,6 & 14,4 & 42,3 \\
\hline 25 & Gravidade e sistema locomotor & 56,1 & 14,2 & 1,8 & 1,1 & 9,0 & 46,4 \\
\hline 17 & Doenças do sistema circulatório & 80,6 & 8,3 & 1,1 & 0,9 & 8,1 & 46,8 \\
\hline 5 & Origem das substâncias minerais e orgânicas & 82,4 & 14,4 & 0,7 & 0,5 & 1,6 & 50,4 \\
\hline \multicolumn{8}{|c|}{ Entre $50 \%$ e $65 \%$ de Acerto } \\
\hline 11 & Caminho do oxigênio no corpo humano & 84,9 & 8,6 & 0,9 & 0,2 & 0,2 & 51,8 \\
\hline 14 & Importância do rim como órgão vital & 79,3 & 8,3 & 1,1 & 0,2 & 0,2 & 53,9 \\
\hline 20 & Sistema nervoso e glandular & 65,1 & 11,7 & 2,5 & 0,5 & 0,5 & 54,0 \\
\hline 24 & Músculos e ossos no movimento & 54,3 & 5,6 & 1,4 & 0,0 & 0,0 & 58,9 \\
\hline 26 & Papel do homem e da mulher na reprodução & 55,2 & 5,4 & 0,7 & 0,5 & 0,5 & 58,9 \\
\hline 1 & Sol e desenvolvimento da vida na Terra & 52,5 & 44,8 & 1,6 & 0,2 & 0,2 & 61,4 \\
\hline 7 & Etapas da digestão & 88,1 & 7,9 & 1,4 & 0,5 & 0,5 & 64,7 \\
\hline \multicolumn{8}{|c|}{ Mais de $65 \%$ de Acerto } \\
\hline 15 & Sangue e digestão e respiração & 86,0 & 8,3 & 1,4 & 0,5 & 3,2 & 65,3 \\
\hline 6 & Relação com os sistemas do corpo & 86,0 & 9,7 & 0,5 & 0,2 & 3,2 & 65,9 \\
\hline 18 & Alteração dos elementos do sangue & 70,9 & 5,6 & 7,7 & 0,9 & 13,7 & 67,9 \\
\hline
\end{tabular}

Somente a título de comparação, verifica-se que em Língua Portuguesa $66,7 \%$ das questões apresentam percentuais de mais de $40 \%$ de divergência entre a previsão dos professores e o acerto dos alunos. Já em Matemática, os dados demonstram que $43,3 \%$ das questões apresentam 
diferença de mais de $40 \%$ entre a previsão dos professores e o acerto real dos alunos.

\section{CONCLUSÕES E RECOMENDAÇÕES}

Com respeito ao livro didático, seria recomendável, para futuras avaliações, que fosse incluída no questionário do professor ou da escola uma questão sobre os livros adotados nos últimos anos e utilizar esta variável na análise estatística, além de prováveis "livros de apoio" adotados pelos docentes na preparação de suas aulas.

Os relatórios estatísticos, particularmente nas conclusões do modelo hierárquico multivariado, indicam que a maior parte da variância do desempenho dos alunos é devida a diferenças individuais (isto é intraescola) do que entre escolas (Cano, 2001, 2001a).

Apenas uma pequena parte da variância individual é explicada pelo modelo estatístico. Além do nível socioeconômico e da escolaridade dos pais, as outras variáveis analisadas não contribuíram muito para explicar esta variância. Certamente, variáveis psicológicas, tais como motivação e grau de desenvolvimento intelectual, determinam em grande parte essas diferenças individuais, porém são difíceis de serem ponderadas no contexto.

Deve-se ressaltar que, embora a variância interescolas seja menor do que a variância intra-escola, é extremamente importante a sua avaliação porque são os fatores relativos a ela que podem e devem ser considerados no delineamento e na implantação das políticas educacionais pela SEEDPR, visando a melhorar o ensino.

Obviamente, não é possível, no âmbito daquela secretaria, influir nas variáveis que atuam diretamente sobre os alunos (por exemplo, sexo, escolaridade dos pais, nível socioeconômico etc.).

Assim, para aperfeiçoar o processo da avaliação, sugere-se que outras características relevantes das escolas sejam investigadas, em particular o número de alunos por turma, a influência do professor por turma ou escola e os livros didáticos empregados. A confecção e expedição de um Boletim da Escola (Paraná, 2001a) não suprem devidamente esse processo.

Apesar das dificuldades em investigar as variáveis consideradas, uma vez que devem ser considerados não apenas os professores e os livros da quarta ou oitava séries, mas todos os anteriores, este estudo parece ser de extrema importância para o real conhecimento da realidade escolar. A 
literatura pedagógica registra estas variáveis como sendo importantes no processo de ensino e aprendizagem.

Um ponto interessante que foi abordado na AVA 1996, e que não aparece nos relatórios subseqüentes, é a análise da participação dos professores no processo, com a exploração da expectativa do professor quanto ao desempenho dos seus alunos e também em relação aos conteúdos ministrados em sala de aula e os contidos na prova.

Verificou-se que a expectativa dos professores não foi atingida devido aos resultados obtidos pelos estudantes, isto é, os professores consideraram que seus alunos se sairiam bem na avaliação, entretanto isso não aconteceu. Isso vale também para os conteúdos que os professores apontaram como tendo sido trabalhados em sala de aula. O que ocorreu pode ter sido em razão das próprias avaliações aplicadas pelos professores, que realizadas de "forma indevida", atreladas a conteúdos repetitivos e de pouco interesse (sem fixação), acabam criando uma cultura de memória evanescente, sem aprendizado real.

Questões como estas devem merecer um maior aprofundamento, considerando que um dos papéis fundamentais da avaliação do sistema é propiciar subsídios para o trabalho pedagógico nas escolas. É difícil inferir o motivo dessa discrepância entre o que os professores esperam e o que trabalham em sala de aula, apenas com os dados que foram levantados no relatório, mas, com toda a certeza, é relevante conhecer em profundidade a situação.

Além do Ensino Fundamental, a AVA trabalhou com a produção de itens e com a avaliação socioeconômica para o Ensino Médio entre 2001 e 2002. No entanto, os resultados dos questionários e da avaliação em si jamais foram estudados e/ou divulgados. Falta, portanto, um empenho grande do governo atual em democratizar o acesso a essas informações, necessárias para a compreensão dos trabalhos realizados desde 1996. É preciso saber como prosseguem os problemas (ou as soluções) para o Ensino Médio 5 .

5 Em 2001, a Secretaria de Estado de Educação do Paraná organizou a Avaliação do Rendimento Escolar para o ano de 2002, incluindo o Ensino Médio. A “Organização do Banco de Itens do Paraná - AVA 2002" contou com a participação de professores da rede pública do Estado. Os professores enviados pelos Núcleos Regionais de Ensino participaram, no primeiro momento, do Seminário de Formação de Professores Elaboradores de Itens de Prova. No segundo momento, os participantes dividiram-se em grupos de acordo com a disciplina e nível de ensino. Cada grupo ficou à disposição de um coordenador que conduziu os trabalhos das oficinas de itens. O objetivo do evento era o de capacitar os educadores para a elaboração de itens para a AVA 2002, a qual seria aplicada em todas as turmas das $4^{\text {as }}$ e $8^{\text {as }}$ séries do Ensino Fundamental e $3^{\text {as }}$ séries do Ensino Médio. Um segundo encontro foi promovido para uma outra oficina de itens. Os 
Finalizando, citamos Bauer e Silva (2005), com questões relevantes para a avaliação:

(...) porque se uma das pretensões da avaliação é subsidiar a formulação de programas para a melhoria da qualidade de ensino, seria de se esperar que os professores fossem, de alguma forma, chamados ao debate sobre a qualidade do ensino. Será possível melhorar a qualidade do ensino sem discutir com os sujeitos que são responsáveis por ela, no cotidiano escolar, os resultados das avaliações? Os professores têm clareza dos parâmetros de qualidade que norteiam [o sistema de avaliação]' ? Sabem como ela está sendo aferida e quais são os resultados dessa aferição? (p. 144)

\section{REFERÊNCIAS BIBLIOGRÁFICAS}

BAUER, Adriana; SILVA, Vandré Gomes da. Saeb e Qualidade de Ensino: algumas questões. Estudos em Avaliação Educacional, v.16, n.31, p.133-152, jan./jun. 2005.

BRASIL. Parâmetros Curriculares Nacionais - Ciências - Ensino Fundamental. Brasília: Ministério da Educação, 1999.

Recomendações para uma Política Pública de Livros Didáticos Brasília: Ministério da Educação/Secretaria de Educação Fundamental, 2001.

CANO, Ignacio. Análise do desempenho na prova em função das características do aluno e da escola - $4^{a}$ série. AVA 2000 - Relatório Técnico. Curitiba: Secretaria de Estado da Educação, 2001.

professores saíram dali com o compromisso de produzir as questões da avaliação, as quais deveriam ser enviadas à SEED para que fossem submetidas à apreciação do orientador. A elaboração dos itens foi uma tarefa minuciosa, que exigiu muito empenho e envolvimento dos professores produtores de itens. As matrizes de referência, com os descritores de competências para cada conteúdo, nortearam os trabalhos para a produção dos itens. Todas as etapas, princípios gerais e específicos deviam ser cuidadosamente estudados, para que o produto final fosse de qualidade. Dependia, em parte, da criatividade e do talento de cada um.

A AVA 2002 foi aplicado. Entretanto, passados três anos, as escolas ainda não receberam os resultados da avaliação. A análise estatística e o desempenho dos alunos são fundamentais para o direcionamento das ações pedagógicas no âmbito escolar. A falta de informações sobre os resultados causou grande frustração entre os professores que participaram do processo de elaboração, como também entre aqueles que esperam os resultados para avaliar o desempenho de seus alunos.

${ }^{6}$ Aqui os autores discutem especificamente o Saeb, mas a interrogação vale, segundo nosso ponto de vista, também para a AVA. 
CANO, Ignacio. Análise do desempenho na prova em função das características do aluno e da escola - 8 série. AVA 2000 - Relatório Técnico. Curitiba: Secretaria de Estado da Educação, 2001a.

COBERN, William. Worldview theory and conceptual change in science education. Science Education, v. 80, n.5, p. 579-610, 1996.

FORQUIM, Jean-Claude. A Nova Sociologia da Educação na Grã-Bretanha: orientações, contribuições teóricas, evolução (1970-1980). In: FORQUIM, J. C. (org.) Sociologia da Educação: dez anos de pesquisas. Petrópolis: Vozes, 1995.

FREITAS, Dirce Nei Teixeira de. A Avaliação Educacional como Objeto de Recomendações Internacionais. Estudos em Avaliação Educacional, v.16, n.31, p. 79-100, jan./jun. 2005.

PARANÁ. Desempenho em Ciências dos Alunos de $8^{a}$ Série do Ensino Fundamental: AVA 1996/97. Curitiba: Secretaria de Estado da Educação, 1997.

Desempenho em Ciências dos Alunos de $4^{a}$ a $8^{a}$ Séries: Ava 1998. Curitiba: Secretaria de Estado da Educação, 1988.

Caderno Ava 2000 - Ciências: uma análise pedagógica. Curitiba: Secretaria de Estado da Educação, 2001. 2001a.

Boletim da Escola. Curitiba: Secretaria de Estado da Educação,

Recebido em: junho 2005

Aprovado para publicação em: agosto 2005 
